\title{
Effects of foot pressure using the elastic band with rings during sit-to-stand in persons with stroke
}

\author{
Young-In Hwang, Ki-Song Kim \\ Department of Physical Therapy, College of Life and Health Science, Hoseo University, Asan, Republic of Korea
}

Objective: Persons with stroke have a tendency to exhibit asymmetric weight-bearing during sit-to-stand because due to the attempt to support themselves with the non-paretic foot. However, there are few devices that can assist with sit-to-stand (STS) performance. This study was designed to investigate the use of the elastic band with rings (EBR) in improving weight-bearing effectively in persons with stroke during STS training.

Design: Cross-sectional study.

Methods: Thirteen stroke survivors participated in the study. An EBR was applied onto the patient during STS activity. The foot pressure was measured before and after wearing the EBR, with a 5-minute rest period between measurements. Subjects were asked to perform each test twice with and without the EBR. Bilateral feet pressures were measured with standing posture being divided into the forward and backward aspects. The foot contact pressure during STS activity was measured with the CONFORMat System.

Results: With EBR, the forward pressure of the affected foot significantly increased while the less-affected forward foot pressure significantly decreased ( $p=0.015$ and $p=0.023$, respectively). The backward foot pressure did not differ significantly in the two limbs, and there was no difference with and without the EBR in terms of the total pressure of the affected foot. There was a significant difference with and without the EBR in the total pressure of the less-affected foot $(p<0.05)$.

Conclusions: STS training with the EBR has been shown to improve weight-bearing of both feet while decreasing the total pressure of the less-affected foot in stroke survivors. Therefore, we suggest that the EBR is a useful tool for STS training for persons with stroke in the clinic.

Key Words: Self-help devices, Stroke, Rehabilitation

\section{Introduction}

For functional independence, individuals with stroke need to achieve sit-to-stand (STS) ability before performing other activities [1]. There is also a tendency toward asymmetric weight-bearing during STS because patients usually support themselves with the non-paretic foot [2]. Engardt and Olsson [3] reported that, following stroke, patients performed more asymmetric weight-bearing with the less-affected leg. It is important to maintain the base of support to prevent falling at the end of STS [4]. Hesse et al. [5] reported that, during STS, the center of gravity was tilted laterally by approximately $78 \%$ before the seat-off and by over $50 \%$ after the seat-off phase in individuals with stroke compared with healthy individuals. The postural asymmetry can cause secondary gait disability after a stroke event $[6,7]$.

STS training is usually introduced early in a rehabilitation program [8-10]. STS is comprised of four phases: 1) the flexion-momentum phase, which comprises the movement initiated before lifting off the buttocks; 2) the momentumtransfer phase, in which the center of mass (COM) of the body is transferred anteriorly and upward, occurring simultaneously with maximal ankle dorsiflexion; 3) the extension phase, when hip extension occurs; and 4) the stabilization

Received: 13 November, 2017 Revised: 21 December, 2017 Accepted: 22 December, 2017

Corresponding author: Ki-song Kim

Department of Physical Therapy, College of Life and Health Science, Hoseo University, 20 Hoseo-ro 79beon-gil, Baebang-eup, Asan 31499, Republic of Korea Tel: 82-41-540-9971 Fax: 82-41-540-9975 E-mail: kskim68@hoseo.edu

(c) This is an Open-Access article distributed under the terms of the Creative Commons Attribution Non-Commercial License (http://creativecommons.org/licenses/ by-nc/4.0) which permits unrestricted non-commercial use, distribution, and reproduction in any medium, provided the original work is properly cited.

Copyright $@ 2017$ Korean Academy of Physical Therapy Rehabilitation Science 
phase, which starts at $0^{\circ}$ of hip extension and continues until the motion is stable [8].

Following a stroke, patients rise from a chair by bearing more weight on the non-paretic foot from phases 1 to 4 , although they improve and perform symmetric STS through visual feedback [3], imagery group training [11], and by altering the foot positions [9]. Bohannon et al. [12] reported that there is at least a $50 \%$ error difference between the perceived body weight born on the foot and the practical distribution in healthy people. Individuals with stroke have a reduced perceived error compared with the practical weight at $50 \%$ of body weight [13]. Cheng et al. [14] reported that, following stroke, patients who had undergone biofeedback training showed improved STS and decreased the risk of falling by distributing their weight symmetrically. Symmetrical movement not only increases weight-bearing by the affected leg but also prevents the learned non-use syndrome and aids in the recovery of functional movement $[14,15]$.

Although research on the use of smart mobile walkers [16] and exoskeletal robots to provide support for STS are currently being actively conducted [17], they are not well acknowledged due to high cost. The elastic band with rings (EBR) is designed to provide strength to the muscles through the axial tension created by the elastic and the ring of the EBR. Therefore, this study aimed to investigate the effects of use of EBR during STS on weight-bearing in persons with stroke.

\section{Methods}

Thirteen stroke survivors were voluntarily involved in the study. All of participants were in-patients at Seoho Hospital in Busan, Republic of Korea. There were 10 males and 3 females; five had right hemiplegia and eight had left hemiplegia. The inclusion criteria were (a) a diagnosis of hemiplegia due to hemorrhagic or ischemic stroke, (b) more than 6 months post-stroke, (c) the ability to follow simple instructions, (d) the ability to walk independently or with an assistive device, and (e) no orthopedic problems involving the lower extremities that would affect gait [18]. The exclusion criteria were (a) a stroke involving more than one hemisphere, (b) more than two strokes, and (c) premorbid or other orthopedic problems that would impede gait patterns [18]. All of them provided their informed consent prior to the execution of the study. Patients demographic information are summarized in Table 1. Hwang et al. [19] designed the EBR, which consists of a 515-cm-long green
Table 1. Characteristics of participants $(\mathrm{N}=13)$

\begin{tabular}{lc}
\hline \multicolumn{1}{c}{ Characteristic } & Value \\
\hline Sex & \\
Male & $10(76.9)$ \\
Female & $3(23.1)$ \\
Affected side & \\
Left & $8(61.5)$ \\
Right & $5(38.5)$ \\
Diagnosis & \\
MCA infarction & $2(15.4)$ \\
Cerebral infarction & $3(23.1)$ \\
ICH & $6(46.2)$ \\
ICH and SAH & $1(7.7)$ \\
Basal ganglia infarction & $1(7.7)$ \\
Age (yr) & $58.00(7.72)$ \\
Height (cm) & $165.47(7.23)$ \\
Weight (kg) & $62.70(9.59)$ \\
Post onset (mo) & $32.00(14.55)$ \\
\hline
\end{tabular}

Values are presented as $\mathrm{n}(\%)$ or mean (SD).

The sum of the percentages does not equal $100 \%$ because of rounding.

MCA: middle cerebral artery, ICH: intracerebral hemorrhage, SAH: subarachnoid hemorrhage.

elastic band and 4 plastic rings made of thin, flexible polyethylene. We used one wrap of the green elastic band with the four plastic rings placed on the anterior tibia, posterior aspect of the knee joint, middle of the thigh, and posterolateral hip joint [19-21]. For consistency, one experienced therapist applied comfortable tension [19,20]. Also, in order to find the most comfortable tension level for each patient, the device was applied onto the patient at least 3 times and the tension that was reported to be the most comfortable by the patient was used.

The foot contact pressure during STS activity was measured with the CONFORMat System (Model \#5330; Tekscan, Boston, MA, USA), a portable interface pressure operating system that can capture the foot pressure distribution and contact area. Before starting, the operating system was checked by loading and unloading it several times. The sensor was equilibrated and calibrated using the instrumentation supplied by the manufacturer. The CONFORMat System was placed on the floor for foot contact after the sensor was prepared. It recorded the foot contact pressure distribution and calculated the mean value from the readings. Measurements were made at a frequency of $10 \mathrm{~Hz}$ for $10 \mathrm{sec}-$ onds using I-Scan ver. 6.20 (Tekscan).

The subjects started in a sitting position with their feet shoulder-width apart. Both feet were parallel so that the lines 


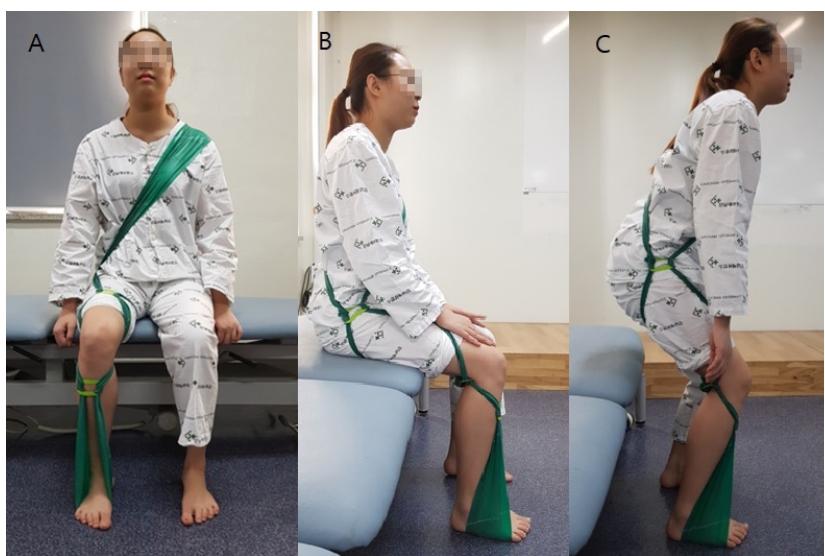

Figure 1. Application of the elastic band with rings on a patient during sit-to-stand activity. (A) Anterior view. (B) Lateral view. (C) Sit-to-stand view.

from the centers of the knee joints to the lateral malleoli were vertical to the CONFORMat [22] (i.e., the knee and ankle joints were both at approximately $90^{\circ}$ ). The seat height for each subject was $100 \%$ of the lower leg length, and the thigh support was at $50 \%$ of the thigh length. The lower leg length was measured from the center of the knee joint to the floor, and the thigh length was the distance between the greater trochanter and lateral knee line $[22,23]$. Initially, the trunk was upright. The bare feet were on the CONFORMat System. When the investigator said "start," the subjects rose from the sitting position. The pressure applied to the soles of the feet was assessed at the start of the sitting state, and was stopped when the hip and knee were extruded to the completed standing posture (Figure 1). An assistant was positioned near the subject to prevent him/her from falling. The foot pressure was measured before and after wearing the EBR, with a 5-minute rest period between measurements. Before testing, an investigator demonstrated the STS activity, and the subjects were allowed to practice it once or twice on the mat. They were also allowed to practice after the EBR was put on and the elastic tension was checked. The mean foot pressure of both feet was compared using the paired t-test. The differences in foot pressure between the values obtained during STS activity with and without the EBR were analyzed using IBM SPSS Statistics ver. 20.0 (IBM Co., Armonk, NY, USA). The level of significance was set at $p<0.05$.

\section{Results}

With EBR, the forward pressure of the affected foot sig-
Table 2. Peak foot pressure in stroke patients on sit-to-stand activity

$(\mathrm{N}=13)$

\begin{tabular}{lrrrr}
\hline \multicolumn{1}{c}{ Foot pressure $\left(\mathrm{N} / \mathrm{cm}^{2}\right)$} & Without EBR & With EBR & $p$-value \\
\hline Affected forward foot & $4.06(1.19)$ & $4.86(1.17)$ & $0.015^{*}$ \\
Less-affected forward foot & $5.01(1.27)$ & $4.40(1.42)$ & $0.023^{*}$ \\
Affected backward foot & $4.63(1.82)$ & $4.56(2.05)$ & 0.851 \\
Less-affected backward foot & $7.52(2.49)$ & $7.21(2.08)$ & 0.511 \\
Total affected foot & $8.69(2.30)$ & $9.43(1.68)$ & 0.148 \\
Total less-affected foot & $12.53(2.97)$ & $11.61(2.42)$ & $0.028^{*}$ \\
\hline
\end{tabular}

Values are presented as mean (SD).

EBR: elastic band with rings. ${ }^{*}<0.05$.

nificantly increased while the less-affected forward foot pressure significantly decreased $(p=0.015$ and $p=0.023$, respectively). The backward foot pressure did not differ significantly in the two limbs, and there was no difference with and without the EBR in terms of the total pressure of the affected foot. There was a significant difference with and without the EBR in the total pressure of the less-affected foot $(p=0.028$; Table 2$)$.

\section{Discussion}

This study measured the pressures of the affected and less-affected foot with and without the EBR during STS activity. With the EBR, the forward foot pressures of both feet were increased significantly, while the total pressure of the less-affected foot was decreased significantly.

One of the reasons for this is that the 'sense of effort' $[24,25]$ is enhanced with the tension of the elastic band on the affected foot. The 'sense of effort' was defined as the sensory experience that leads the muscle to control the production of power [25]. The sense of effort is produced through both feed-forward and feedback mechanisms. With the EBR, the tension or force from the feedback neural signals (i.e., the ascending sensory information) [24,26] is used to increase the stability of the ankle, knee, and hip joints to increase weight-bearing on the affected side and decrease the weight-bearing on the less-affected side.

Additionally, the forward pressure of the affected foot was increased selectively compared with the backward pressure. Characteristically, stroke survivors tend to invert the affected foot $[27,28]$. The EBR supports the transverse and longitudinal arches to produce better foot position [19], which provides sufficient resistance to the floor and proprioception on the affected foot in individuals with stroke. 
Moreover, it might provide sensory input to the affected forward foot to supplement sensory deficits, consequently decreasing the forward pressure of the less-affected foot. According to Brière et al. [2], it is better to perceive the affected side than to increase the knee effort. When patients first attempt to stand from a sitting position following a stroke, they tend to load their weight on the less-affected side due to non-use syndrome [29,30]. With the EBR, perception of the affected side might reduce the learned non-use syndrome.

To achieve STS, the COM of the body must be moved forward during the preparatory phase and reach a maximum velocity before the seat-off phase [31]. This maximally increases the vertical force of the foot, while the trunk moves forward to reach the seat-off phase [31,32]. As the vertical force increases, the COM should move forward to achieve STS. We postulated that the forward pressure of both feet would increase. With the EBR, however, the pressure of the less-forward foot decreased significantly. This is as important as increasing the pressure of the affected forward foot because the pressure of the less-affected foot could not decrease without sufficient perception of the affected foot. Taub et al. [30] and Bohannon and Larkin [33] also reported that individuals with stroke achieved symmetrical movement by increasing of their attention and effort. By wearing the EBR, stroke survivors increased their attention to the affected foot and increased the muscle effort via the tension of the elastic band.

In this study, the subjects started with the knee directly above the ankle. This increases the duration, the distance of the COM, and the gastrocnemius and soleus activity compared with having the backward foot about $10 \mathrm{~cm}$ behind this vertical line during STS [22]. It is relatively difficult compared with having one foot backward, but the position could be selected based on function. The foot directly under the knee causes mono-articular muscles, such as the vastus medialis, tibialis anterior and soleus, to lift the body mass to a greater distance [22].

The patients were instructed to assume a symmetrical foot position during STS, although symmetric and asymmetric training have different clinical advantages. Some authors suggest that symmetric practice not only increases weightbearing on the affected side but also prevents learned nonuse syndrome and assists in the recovery of functional movement $[14,15]$. In comparison, asymmetric STS training with the affected foot behind the less-affected foot increases weight-bearing on the affected side $[9,34,35]$ and results in greater activity of the tibialis anterior and quadriceps. Farqalit and Shahnawaz [36] also reported that an asymmetrical foot position improved balance and upright mobility in those affected by stroke. Therefore, future investigations need to examine the effects of symmetric and asymmetric foot positions in STS training with the EBR on the foot pressure and muscle activity in persons with stroke.

\section{Conflict of Interest}

The authors declared no potential conflicts of interest with respect to the authorship and/or publication of this article.

\section{References}

1. Camargos AC, Rodrigues-de-Paula-Goulart F, Teixeira-Salmela LF. The effects of foot position on the performance of the sit-tostand movement with chronic stroke subjects. Arch Phys Med Rehabil 2009;90:314-9.

2. Brière A, Nadeau S, Lauzière S, Gravel D. Perception of weightbearing and effort distribution during sit-to-stand in individuals post-stroke. Percept Mot Skills 2013;117:1208-23.

3. Engardt M, Olsson E. Body weight bearing while rising and sitting down in patients with stroke. Scand J Rehabil Med 1992;24: 67-74.

4. Vander Linden DW, Brunt D, McCulloch MU. Variant and invariant characteristics of the sit-to-stand task in healthy elderly adults. Arch Phys Med Rehabil 1994;75:653-60.

5. Hesse S, Schauer M, Malezic M, Jahnke M, Mauritz KH. Quantitative analysis of rising from a chair in healthy and hemiparetic subjects. Scand J Rehabil Med 1994;26:161-6.

6. Taylor D, Ashburn A, Ward CD. Asymmetrical trunk posture, unilateral neglect and motor performance following stroke. Clin Rehabil 1994;8:48-52.

7. Turnbull GI, Charteris J, Wall JC. Deficiencies in standing weight shifts by ambulant hemiplegic subjects. Arch Phys Med Rehabil 1996;77:356-62.

8. Schenkman M, Berger RA, Riley PO, Mann RW, Hodge WA. Whole-body movements during rising to standing from sitting. Phys Ther 1990;70:638-48; discussion 648-51.

9. Roy G, Nadeau S, Gravel D, Malouin F, McFadyen BJ, Piotte F. The effect of foot position and chair height on the asymmetry of vertical forces during sit-to-stand and stand-to-sit tasks in individuals with hemiparesis. Clin Biomech (Bristol, Avon) 2006; 21:585-93.

10. Jung DK, Chung Y. The effect of hip joint strengthening exercise using proprioceptive neuromuscular facilitation on balance, sit to stand and walking ability in a person with traumatic brain injury: a case report. Phys Ther Rehabil Sci 2017;6:96-104.

11. Lee J, Hwang S, Ahn S. Effects of sit-to-stand imagery group training on balance performance in individuals with chronic hemiparetic stroke: a randomized control trial. Phys Ther Rehabil Sci 2016;5:63-9. 
12. Bohannon RW, Waters G, Cooper J. Perception of unilateral lower extremity weightbearing during bilateral upright stance. Percept Mot Skills 1989;69:875-80.

13. Bohannon RW, Tinti-Wald D. Accuracy of weightbearing estimation by stroke versus healthy subjects. Percept Mot Skills 1991;72:935-41.

14. Cheng PT, Wu SH, Liaw MY, Wong AM, Tang FT. Symmetrical body-weight distribution training in stroke patients and its effect on fall prevention. Arch Phys Med Rehabil 2001;82:1650-4.

15. Aruin AS, Hanke T, Chaudhuri G, Harvey R, Rao N. Compelled weightbearing in persons with hemiparesis following stroke: the effect of a lift insert and goal-directed balance exercise. J Rehabil Res Dev 2000;37:65-72.

16. Kim I, Cho W, Yuk G, Yang H, Jo BR, Min BH. Kinematic analysis of sit-to-stand assistive device for the elderly and disabled. IEEE Int Conf Rehabil Robot 2011;2011:5975438.

17. Rajasekaran V, Vinagre M, Aranda J. Event-based control for sit-to-stand transition using a wearable exoskeleton. IEEE Int Conf Rehabil Robot 2017;2017:400-5.

18. Hwang YI, An DH, Yoo WG. Effects of the Dual AFO on gait parameters in stroke patients. NeuroRehabilitation 2012;31:38793.

19. Hwang YI, Yoo WG, An DH. Effects of the Elastic Walking Band on gait in stroke patients. NeuroRehabilitation 2013;32: 317-22.

20. Patil P, Rao S. Effects of Thera-Band ${ }^{\circledR}$ elastic resistance-assisted gait training in stroke patients: a pilot study. Eur J Phys Rehabil Med 2011;47:427-33.

21. Veneri D. 2004 Thera-Band ${ }^{\circledR}$ Most Creative Use Contest First Place Winner: Thera-Band ${ }^{\circledR}$ Assist with Swing Phase of Gait [Internet]. Akron (OH). The Hygenic Corporation, 2004 [cited 2011 Mar 28]. Available from: https://media.lanecc.edu/users/ howardc/PTA204L/204LThera-Band.pdf.

22. Khemlani MM, Carr JH, Crosbie WJ. Muscle synergies and joint linkages in sit-to-stand under two initial foot positions. Clin Biomech (Bristol, Avon) 1999;14:236-46.

23. Yoon JY, Kim KM, Chang MY, Yoo WG, Oh JS, An DH. Foot pressure and trunk muscle activity during reaching tasks performed by seated hemiplegia patients. J Phys Ther Sci 2011;23: 525-9.

24. Roland PE, Ladegaard-Pedersen H. A quantitative analysis of sensations of tension and of kinaesthesia in man. Evidence for a peripherally originating muscular sense and for a sense of effort. Brain 1977;100:671-92.

25. Simon AM, Ferris DP. Lower limb force production and bilateral force asymmetries are based on sense of effort. Exp Brain Res 2008;187:129-38.

26. Park KS, Choi JD. The effect of balance training with plantar flexor stretching on range of motion, balance, and gait in stroke patients: a randomized controlled pilot trial. Phys Ther Rehabil Sci 2015;4:66-72.

27. O'Sullivan SB, Schmitz TJ. Physical rehabilitation: assessment and treatment. 4th ed. Philadelphia: F.A. Davis; 2001. p. 532.

28. Daher N, Lee S, Yang YJ. Effects of elastic band orthosis (aider) on balance and gait in chronic stroke patients. Phys Ther Rehabil Sci 2013;2:81-6.

29. Lee MY, Wong MK, Tang FT, Cheng PT, Chiou WK, Lin PS. New quantitative and qualitative measures on functional mobility prediction for stroke patients. J Med Eng Technol 1998;22: 14-24.

30. Taub E, Miller NE, Novack TA, Cook EW 3rd, Fleming WC, Nepomuceno CS, et al. Technique to improve chronic motor deficit after stroke. Arch Phys Med Rehabil 1993;74:347-54.

31. Roebroeck ME, Doorenbosch CA, Harlaar J, Jacobs R, Lankhorst GJ. Biomechanics and muscular activity during sit-tostand transfer. Clin Biomech (Bristol Avon) 1994;9:235-44.

32. Boukadida A, Piotte F, Dehail P, Nadeau S. Determinants of sit-to-stand tasks in individuals with hemiparesis post stroke: a review. Ann Phys Rehabil Med 2015;58:167-72.

33. Bohannon RW, Larkin PA. Lower extremity weight bearing under various standing conditions in independently ambulatory patients with hemiparesis. Phys Ther 1985;65:1323-5.

34. Brunt D, Greenberg B, Wankadia S, Trimble MA, Shechtman O. The effect of foot placement on sit to stand in healthy young subjects and patients with hemiplegia. Arch Phys Med Rehabil 2002;83:924-9.

35. Lecours J, Nadeau S, Gravel D, Teixera-Salmela L. Interactions between foot placement, trunk frontal position, weight-bearing and knee moment asymmetry at seat-off during rising from a chair in healthy controls and persons with hemiparesis. J Rehabil Med 2008;40:200-7.

36. Farqalit R, Shahnawaz A. Effect of foot position during sit-tostand training on balance and upright mobility in patients with chronic stroke. Hong Kong Phys J 2013;31:75-80. 